\title{
LA AUTOFICCIÓN: UNA APROXIMACIÓN TEÓRICA. ENTRE LA RETÓRICA DE LA MEMORIA Y LA ESCRITURA DE RECUERDOS
}

\author{
THE AUTOFICTION: A THEORETICAL APPROACH. BETWEEN THE \\ RHETORICAL OF MEMORY AND THE WRITING OF SOUVENIRS
}

\author{
Julia Musitano \\ UNR-CONICET. Rosario, Argentina \\ luchinaj@hotmail.com
}

\begin{abstract}
Resumen: A lo largo de cuatro apartados se realiza una aproximación teórica a la autoficción teniendo en cuenta el estado actual de la cuestión sobre el tema y tendiendo redes hacia otras líneas teóricas que complejizan y profundizan el análisis. La hipótesis principal que articula el texto es que a partir de las diferencias entre "la retórica de la memoria" y "la escritura de los recuerdos", la autoficción propone la potenciación del carácter ambiguo y disruptivo de la segunda en detrimento del carácter sistemático y organizativo de la primera.
\end{abstract}

Palabras clave: Autoficción, teoría literaria, siglo XXI, recuerdo/memoria.

\begin{abstract}
Through four sections, this paper would realize a theoretical approach to autofiction taking into account the actual state of the investigation about the matter and laying networks to others theoretical lines that would allow us to go further in the analysis. The main hypothesis that articulates the text is that from the differences between "the memory"s rhetorical" and "the writing of souvenirs", the new genre proposes the strengthening of the ambiguous character of the second, in behalf of the systematic one of the first.
\end{abstract}

Keywords: Autofiction, literary theory, XXI century, souvenir/memory.

Recibido: 04.11.2015. Aceptado: 15.02.2016. 
Alors que l'ego-littérature prétend fallacieusement représenter la "realité vécue" comme un spectacle, un reality show, le roman du je désigne le réel comme un «impossible». Là où l' autofiction prétend découvrir les origines, l'identité, la vérité du sujet, l'hétérobiographie ne traduit qu' un «sentiment radical de perte» ${ }^{1}$ (Gasparini, 2008, p. 231).

\section{Introducción}

T A AUtoficción -género paradójico por excelencia, que vacila entre dos _mundos, el de la autobiografía y el de la novela, y que no nos permite como lectores discernir entre verdad o invención- viene a registrar una paradoja contemporánea: la espectacularización de la intimidad, la imbricación de los espacios, los límites laxos entre lo público y lo privado, entre la realidad y la ficción. La autoficción no es ajena a las escrituras confesionales que fueron absorbidas por la cultura del espectáculo porque sus búsquedas estéticas son compatibles con esa telerrealidad. En una época en que lo íntimo se revela en todos lados, la novela también ha dejado de novelar (Cusset, 2007, pp. 197-211). Las relaciones entre verdad y mentira, ficción y realidad que nunca fueron sencillas de dilucidar, hoy vuelven a complicarse.

Los relatos autoficticios son relatos ambiguos porque no se someten ni a un pacto de lectura verdadero, ya que no hay una correspondencia total entre el texto y la realidad como la que postula el pacto referencial, ni ficticio, porque se mantienen en ese espacio fronterizo e inestable que desdibuja las barreras entre realidad y ficción. La autoficción constituye un subgénero híbrido o intermedio que comparte características de la autobiografía y de la novela. En ellas se alteran las claves de los géneros autobiográfico y novelesco y el pacto se concibe como el soporte de un juego literario en el que se afirman simultáneamente las posibilidades de leer un texto como ficción y como realidad autobiográfica.

Me propongo realizar, a lo largo de cuatro apartados, una aproximación teórica propia al género teniendo en cuenta el estado de la cuestión actual

${ }^{1}$ En tanto que la literatura del yo pretende falazmente representar la "realidad vivida" como un espectáculo, un reality show, la novela del yo designa lo real como un "imposible". Allí donde la autoficción pretende descubrir los orígenes, la identidad, la verdad del sujeto, la heterobiografía no traduce sino un "sentimiento radical de pérdida". (La traducción es mía). 
sobre el tema y estableciendo prioridades en relación a pensar la autoficción como una forma paradójica de escribir la propia vida. A mi modo de entender, en esta clase de textos no importa tanto si lo que se cuenta es mentira o si el contenido es realmente autobiográfico, como que la ficción de la autonovela se funde en el carácter imaginario de la irrupción de los recuerdos. Es decir, la hipótesis que articula esta aproximación es que en la autoficción, a diferencia de la autobiografía, hay una potenciación de los mecanismos del recuerdo en detrimento del carácter sistemático y organizativo de la memoria; y que es esto justamente lo que permite la entrada de la ficción en el relato de la propia vida.

Ahora bien, sabemos que la autoficción hace su primera aparición (a escondidas) en aquel cuadro de doble entrada por el que Lejeune intenta establecer la relación de identidad entre el nombre del personaje y del autor y derivar de allí la naturaleza del pacto -novelesco o autobiográfico- al que pertenece. Una de las casillas vacías, en la que el nombre del personaje coincide con el nombre del autor, pero el pacto es novelesco, no propicia ninguna definición porque el teórico no puede pensar en un ejemplo en el que el héroe de la novela tenga el mismo nombre que el autor. En ese vacío clasificatorio, el escritor francés Serge Doubrovsky concibe por primera vez la autoficción ${ }^{2}$. Llena la casilla con un neologismo de su creación en las advertencias de la novela Fils. El concepto original de Doubrovsky, que con los años fue mutando, programa una doble recepción, referencial respecto al pasado del héroe-narrador, y ficcional respecto al marco narrativo que justifica la evocación memorial.

Autobiographie? Non. (...) Fiction d' évenements et des faits strictement réels; si l' on veut autofiction, $d^{\prime}$ avoir confié le langage d' une aventure a $l^{\prime}$ aventure du langage, hors sagesse et hors syntaxe du roman traditionnel ou nouveau (Doubrovsky, 2001, p. 3).

\footnotetext{
${ }^{2}$ Aunque hay discusiones sobre si en realidad fue Jerze Kosinsky el primero en usar el término en 1966 para definir su novela $L^{\prime}$ Oiiseau Bariolé, Doubrovsky fue el primero en usarlo con el sentido que hoy le damos.

${ }^{3}$ ¿Autobiografía? No [...] Ficción de acontecimientos y de hechos estrictamente reales; si se quiere autoficción, de haber otorgado al lenguaje de una aventura la aventura del lenguaje, por fuera de la seriedad y la sintaxis de la novela tradicional o nueva. (La traducción es mía).
} 
Esa aventura del lenguaje se refiere a una sola cosa, al psicoanálisis. El héroe y el analista dialogan imitando una sesión de análisis. El análisis justifica la pulsión autobiográfica y la ordena. Levanta las censuras que presenta la memoria y pone en funcionamiento la anamnesis que desborda al sujeto. A partir de la estrategia psicoanalítica, se crea una lengua propia para contar una vida. El psicoanálisis sacude la noción misma de la identidad personal que funda la escritura del yo cuando pone en evidencia el carácter inasible, fragmentario e infantil del yo. El canal que separa al autor actual, narrador, del individuo pasado, narrado, parece desde allí infranqueable. El objetivo de la cura psicoanalítica, explica Philippe Gasparini en relación a la teoría de Doubrovsky, es disociar la imagen que el sujeto se hace de sí mismo por hacerle tomar conciencia de los eventos que están en el origen de su neurosis, mientras que la autobiografía, en cambio, organiza los recuerdos en tren de efectuar una psicosíntesis que le otorga sentido a la existencia (Gasparini, 2008, p. 58).

Sin embargo, como a Doubrovsky le interesa distinguir la autoficción de la autobiografía y de la novela autobiográfica, tiende a despejar el terreno de la ambigüedad propia del género (novela y autobiografía simultáneamente) e inclina la novela autobiográfica hacia la ficción, convirtiendo a la autoficción en una versión posmoderna de la autobiografía, y es así como liga el fenómeno al pacto referencial, cancelando de este modo toda inestabilidad. A partir de esta definición, surgieron varias aproximaciones a la nueva forma literaria: entre ellas, las de Gérard Genette, Vincent Colonna, Philippe Gasparini, Philippe Lejeune, Philippe Vilain, Philippe Forest, Manuel Alberca y Marie Darrieussecq.

Gérard Genette, por su lado, en Ficción y dicción, esboza un acercamiento a la autoficción a partir de una fórmula: "Yo, autor, voy a contaros una historia cuyo protagonista soy yo, pero que nunca me ha sucedido" (1993, p. 70), que señala la contradicción inherente del género (aunque se podría pensar no como contradicción sino como paradoja, ya que supone la afirmación de los dos sentidos a la vez sin exigir distinción). Sin embargo, habría que tener en cuenta que el autor francés propone dos tipos de discursos: el factual, donde hay identidad entre autor y narrador, y el de ficción donde no la hay. Entonces, su definición de autoficción contradice su tesis principal ya que en un relato de ficción, según él, la identidad no- 
minal es indefendible. Y es esta justamente la apuesta de la autoficción: A es +/- N (disociación + identidad).

Vincent Colonna, discípulo de Genette, en Autofiction et autres mythomanies littéraires (2004) define la autoficción como la invención literaria de una existencia, la ficcionalización del yo, es decir, hacer del yo un elemento literario, un sujeto imaginario. Sin embargo, entiendo que en el proceso autoficcional se trata justamente de lo inverso: "mi" existencia se hace ficción, invento porque me expongo a lo desconocido. Mi existencia no se convierte en imaginaria, sino que se trata de una exposición ficticia sobre el carácter real de mi existencia. Se establece la identidad canónica autobiográfica entre autor, narrador y personaje, pero al mismo tiempo se rompe con ella, al presentarse como ficción, verdadero y falso simultáneamente. Nuevamente esta tentativa teórica inclina la balanza, pero hacia el modo ficcional, es decir, de forma incompatible con la definición original de Dubrovsky. Aquí, Colonna plantea la identidad nominal entre autor y héroe, pero como una proyección del primero en situaciones imaginarias. La denomina autofabulation porque la concibe como una historia irreal, indiferente a la verdadera, es decir, exige una ausencia total de referencia autobiográfica, restringiendo, de esta manera, el campo de la autoficción.

Tanto Genette como Colonna proponen una base genérica muy frágil para soportar el peso de una práctica que se basa en la tensión fundamental entre realidad y ficción. Únicamente basta la identidad onomástica, sin importar si lo que se cuenta es una historia ficticia, para que haya autoficción. Como bien dice Arnaud Schmitt, no preguntarse sobre lo real es no preguntarse sobre lo inherente a la autoficción (2010, p. 62).

En este orden de interrogaciones, dos textos llaman también la atención: El pacto ambiguo. De la novela autobiográfica a la autoficción (2007) de Manuel Alberca y L'autofiction en théorie (2009) de Philippe Vilain. El primero porque si bien se mantiene en esa concepción que describía más arriba, logra darle un giro a la discusión, planteando la autoficción como un pacto ambiguo o como un antipacto, sin decantarlo hacia el lado de lo referencial ni hacia el de lo novelesco; y la piensa en su propio mestizaje. El segundo porque plantea que la ficción y la realidad no pueden distinguirse sino que son dos formas de expresión de una misma experiencia: aquella de la imposibilidad de lo real. Es decir, el proceso de desdoblamiento de hacer 
aparecer una vida como una novela evocaría necesariamente la fábula de nuestra propia existencia.

También autores como Philippe Gasparini o Marie Darrieussecq se aproximan al estudio del nuevo género. El primero recupera el concepto de novela autobiográfica, no para distinguirla de la autoficción, sino para considerar la última como una novela autobiográfica posmoderna. Y la segunda, discípula de Genette, piensa a la autoficción como una variante subversiva de la novela en primera persona ya que se transgrede el principio de no identificación entre narrador y autor al utilizar el mismo nombre propio. Darrieussecq establece que la autoficción se diferencia de la autobiografía por la elección de la ficción.

Gasparini dedica dos libros enteros a la teorización sobre el género. En Est-il je? (2004) expone fundamentos y procedimientos narrativos que se llevan a cabo en el proceso de escritura de las autoficciones con modos estructuralistas. En Autofiction. Une aventure du langage (2008), realiza no sólo un recorrido exhaustivo, conciso y claro por las diferentes nociones sobre el género, sino que también expone una definición propia que él llama autonarración. Entiende que la autoficción se presenta como el signo de un progreso porque permite el ingreso de las escrituras del yo a la modernidad (295). La obra de Gasparini tiene el mérito de sintetizar los trabajos sobre el tema, con objetividad, claridad que otorga al género los cimientos teóricos que necesita, sin embargo parece presentar más inconvenientes que ventajas al presentar una sucesión de posiciones teóricas que muestran, por las contradicciones que se plantean entre ellas, un estancamiento teórico más que avances. Y además, la definición de autonarración que propone reclama aún más para ser contundente. El auto sin ficción viene a ser un vehículo literario no funcional, perfecto para un museo. La ficción de la autoficción se aparece más como una simple traducción de lo real o de recreación del referencial (Vilain, 2009, p. 18).

Algunas de estas líneas teóricas se basan en concepciones de inclinación estructuralista que han logrado estancar las posibilidades teóricas que permite el nuevo género. Los teóricos que siguen esta tendencia sobre el tema tienden a estabilizar categorías literarias que son por naturaleza inestables, a suprimir la indiscernibilidad propia de la autoficción e intentan apresar rígidas técnicas narrativas en manuales sobre cómo escribir la propia vida (qué tiempos verbales utilizar, cómo elegir el paratexto, el peritexto y el 
epitexto, cómo jugar con los dos registros, el autobiográfico y el novelesco, además de definir y someter al género a interminables categorías, clasificaciones y gradaciones). Elijo no inscribir la hipótesis de trabajo en esta tradición y pensar al género en su propia inestabilidad como una perspectiva más de las escrituras del yo, como una de las tantas posibilidades que se ponen en funcionamiento cuando alguien quiere contar su propio pasado, cuando un yo se escribe.

No preocuparse tanto sobre cómo la autobiografía y la novela se fusionan en un mismo relato, o cómo separamos la ficción de la realidad para poder discernir frente a qué género estamos parados, implica, entonces, revisar los modos en que ciertos mecanismos -recuerdo, memoria, verdad y mentira- se entrecruzan en algunos relatos que decidimos llamar autoficticios, y evaluar si son muy divergentes de aquellos que aparecen en la autobiografía o en la novela. Es decir, habría que preguntarse si la autoficción, que no ha logrado, desde su concepción hasta hoy, una definición exacta, válida y contundente que la coloque como un género literario como la autobiografía o la novela, conserva su pertinencia teórica. ¿Viene a renovar el género autobiográfico, o se constituye por sí misma como un género literario al margen de sus dos progenitores?

\section{2. "Un contrato de la feinte"}

Afirmar que la autoficción es una mezcla de ficción y realidad nos sirve de muy poco porque distinguir en el discurso realidad y ficción supone estancarse teóricamente en discusiones que no aportaron resultados productivos. Esta oposición se supera en el engendramiento del texto mismo y da como resultado un objeto que modifica lo real y lo imaginario. En este caso, las autoficciones son relatos ambiguos y como tales no se les puede exigir que se sometan a la distinción entre una dimensión y otra. El trabajo que la autoficción realiza con los acontecimientos pasados y verdaderos neutraliza la fuerza de la oposición. Esto -digámoslo una vez más- no se reduce a la mezcla de realidad y ficción: se trata de la afirmación simultánea de ambas dimensiones y la incapacidad explícita de discernirlas.

Aquí surge un problema para la teoría de escrituras autobiográficas: la cuestión del referente. Es decir, ¿hasta qué punto hay una referencia clara 
fuera del texto? ¿O en qué momento ese referente se pierde y se convierte en una ilusión? ¿Cuándo sabemos si el autor nos dice la verdad? ¿Es posible comprobarlo dentro de la misma escritura o hay que buscarlo por fuera del texto? ¿Existe un contrato de lectura con el lector o está en este último depositada la fidelidad a la verdad? La autoficción nace en la paradoja de la identidad onomástica -el pacto autobiográfico se cumple- y de la atestación de ficción -el novelesco también. Si la autoficción viene a subvertir los códigos de sus dos grandes progenitores, deberían renovarse viejas premisas que ya no sirven para pensar en una forma literaria creada a partir de sus propias contradicciones. Y cuando digo viejas premisas estoy pensando específicamente en la noción de pacto de Lejeune (1975). Recordemos que para Lejeune, el tema de la verdad es indiscutible. El que se escribe, dice la verdad y nada más que la verdad; y eso está en los fundamentos de su teoría sobre el pacto. Esa identidad autobiográfica que planteaba el teórico francés ya no nos sirve si pensamos la vida siempre en potencial de devenir, y no como algo estancado, homogéneo, o como una unidad real y bien definida; muy lejos de ese sujeto cartesiano entendido como presencia ante sí, unidad y fundamento de verdad. La deconstrucción de la noción clásica del sujeto, a pesar de sus formas varias, tiene como horizonte la apertura para una comprensión de una subjetividad siempre en devenir, de procesos de subjetivación que no atienden a ninguna finalidad preconcebida porque ellas sólo se procesan en el acontecer continuo y aleatorio de la propia vida. Así como se formula una deconstrucción de la noción de sujeto tradicional, esto afecta asimismo la noción de sujeto autobiográfico (Duque-Estrada, 2009, p. 39).

Alberca, por ejemplo, plantea que la autoficción viene a poner a prueba la teoría de Lejeune porque el autor de autoficciones se protege bajo un pacto narrativo a la carta, un menú elaborado a su gusto, que resulta ser en muchos sentidos un antipacto autobiográfico (2007: 166). Y agrega que según cómo el lector lo resuelva, se decantará hacia uno u otro estatuto. Si bien acordamos en la ambigüedad del pacto, que se concibe en los textos autoficticios, y en la noción de antipacto, que es pertinente para definir una nueva forma creada justamente en la contradicción de la casilla vacía (referida a la naturaleza del pacto), es necesario entonces -para poder progresar en el pensamiento teórico sobre la autoficción- observarla desde una perspectiva crítica del texto de Lejeune. 
No debemos perder de vista que esa identidad planteada por Lejeune está pensada únicamente por fuera del texto, como un contrato de lectura, en el orden de la referencialidad pura: la firma. La firma se constituye en la imagen misma de lo real, explica Catelli, y es por eso que no se juega con la verosimilitud o con un efecto de lo real (2007, p. 293). Y Nicolás Rosa agrega que lo que sucede con la concepción de Lejeune es que se confunde la búsqueda desesperada de la certificación de la verdad con la verdad misma. La incertidumbre genérica propia de la autobiografía nos hace creer, explica Rosa, que la ficción se ausenta del discurso, y que todo lo que el yo cuenta es verdad porque contamos con la verificación del carácter real de su existencia gracias a la firma que lo constata (2004, p. 32). El proceso de densificación que sufre el yo en las escrituras autobiográficas logra que se simule una continuidad en algo que de por sí es discontinuo (la memoria y el recuerdo) y, por ende, tiende a la flexibilidad, a la ficcionalización. Aquí, habría que hacer una digresión para aclarar que de ningún modo esto supone que el carácter ficcional de un texto dependa exclusivamente de su autor, y que, para citar a Barthes, el sujeto ya no es pensado como pretensión ideológica de unidad, sino como apertura radical a la lectura. Marcelo Topuzian, en Muerte y resurrección del autor, plantea que el acontecimiento de la lectura debe concebirse como descentramiento radical del sistema justamente porque es esto lo que da lugar a la mezcla de códigos a los que apunta, según Barthes, cualquier intento de liberación del lenguaje. Y el sujeto, aclara Topuzian, opera en esa mezcla (2014, p. 125).

Por esto, Rosa propone un contrato aleatorio en lugar de la noción de pacto o contrato consensual.

Este contrato aleatorio regido por las leyes del cálculo conjetural del sujeto en relación al otro, establecería reglas no consensuales que sólo se articularían de acuerdo con las estrategias de cada sujeto [...]. Un contrato de este tipo presupone la existencia de un imaginario social y de un régimen de intercambio de valores simbólicos, pero no implica un contrato de veridicción y un contrato fiduciario como lo propone Greimas sobre el contenido enunciativo y el estatuto veridictivo del enunciado. Sería un contrato de la feinte, donde el juego imaginario de la simulación del sujeto estaría sostenido sobre las leyes simbólicas del simulacro. [...] Se finge romper para unir (en la identificación) o se finge establecer para romper (en la resistencia) (Rosa, 2004, p. 36). 
La autorreferencialidad de la persona real que se presenta como instancia de la verdad se dilata apenas comienza el proceso reflexivo en que se escribe sobre sí mismo. En un capítulo de Lo que queda de Auschwitz, Agamben distingue testigo de testimonio. El testigo testimonia a favor de la justicia -no sabemos bien si es a favor de la verdad-, en cambio el testimonio "vale en lo esencial por lo que falta en él" (2000, p. 18). La persona que firma y establece con el lector un contrato o un pacto de lectura, lo hace en el sentido jurídico del término, responsabilizándose por lo que dice, pero mucho más allá de eso, y mucho más acá del lenguaje, esa persona se escribe, y por el hecho de escribirse, ya no puede hacerse cargo de la verdad que propone contar y se pierde en el pasaje de los recuerdos a la escritura. El testimonio, dice Agamben siguiendo a Lyotard, implica la imposibilidad de testimoniar. Del mismo modo, escribir la propia vida implica también su propia imposibilidad.

La escritura no puede representar el pasado de manera viva porque es imposible narrar la historia de una primera persona que sólo existe en el presente de la enunciación. Por ende, confundimos la escritura autoficticia con estrategias de figuración, por un lado, o con contratos jurídicos, por otro. El pasado lo podemos contar, escribir, pero no podemos reescribirlo. El simple relato del pasado es únicamente posible en el marco de la restitución de un objeto muerto porque la resurrección auténtica, viva de un pasado, es imposible. Reescribir significa reconstituir los eventos pasados conformes a la verdad, recuperar el pasado (De Toro, 1999).

Topuzian, por su parte, en el intento de mostrar las condiciones contemporáneas del retorno del autor, entiende que lejos de desaparecer, el autor nos demuestra, hoy, que no se corresponde con la personalidad del que escribe (que los medios de comunicación y el mercado editorial se encargan de consagrar); que tampoco es un rasgo más de la serie de los enunciados; ni el foco de origen del sentido; y menos esa figura de autor construible en un marco institucional. La autoría literaria es más bien un efecto del juego de los textos, se realiza en los textos, pero apunta a un más allá de ellos. Si, para Topuzian, se puede hablar de algún retorno del autor (de su resurrección) no está en los rasgos identitarios del que escribe sino que es en su relación con la verdad (2014, p. 367). La verdad de los textos literarios, entonces, no es del orden del sentido, no puede constituirse como saber, no es un efecto de una construcción verbal; muy por el contrario: es 
un acontecimiento. La manifestación de una verdad literaria es el resultado de un procedimiento (no construible en términos de estilo) que pone en tensión los materiales verbales hasta empujarlos hacia lo no comunicable, lo asignificante (la fuerza deceptiva, diría Barthes).

Si hay algo propio en el autor, es precisamente aquello que lo hace impersonal, o sea, que declare una verdad literaria, que lo es en el sentido de que está dirigida a cualquiera y podría venir de cualquiera radicalmente (Topuzian, 2014, p. 367).

Dice Vilain que la realidad es en sí una ficción y la ficción que refleja una realidad redobla la ficción. La autoficción suscribe un proyecto: la novela en la que un escritor finge transformar la verdad vivida haciendo aparecer la naturaleza ficticia, lejos de hacer del libro el lugar donde se construye una identidad, pone a prueba una inquietud perdida, un vértigo donde se cumple y se disuelve a la vez. El juego que se juega es el de un sacrificio, de una puesta en muerte, al estilo demaniano ${ }^{4}$. Esa identidad que propone la escritura, que sólo se pone en juego en el proceso de escribir una vida, y que no es anterior a ella, surge no tanto sobre la retrospección -la mirada hacia atrás de una vida-, sino sobre la prospección que acompaña la acción inventiva de la escritura.

Así, escribir sobre uno mismo sería ese esfuerzo, siempre renovado y siempre fallido, de dar voz a aquello que no habla, de dar vida a lo muerto, dotándolo de una máscara textual (Molloy, 1966, p. 11). La figura de la prosopopeya como la imposición de una máscara a lo informe es también una decisión en el tiempo, y por ende, siempre va a estar presionada por los intereses de un pasado. Un pasado que aún no concluyó. Y justamente

\footnotetext{
${ }^{4}$ En este sentido, retomo la figura de la prosopopeya con la que trabaja Paul de Man. Enfoca el problema en la cuestión del referente, es decir, si es la figura la que depende de él o viceversa, o bien si se trata de la ilusión de la referencia. En el texto "La autobiografía como desfiguración", De Man viene a cuestionar la índole misma del género a partir de proponer que no existe un yo previo a la escritura, sino que el yo resulta del relato de la propia vida. Y además, alega que la autobiografía no es un género literario sino una figura de lectura: la prosopopeya. Un movimiento por el cual lo informe sufre una desfiguración, explica Catelli. Es decir, a lo informe se le colocará una máscara cuya identidad se ignora. La prosopopeya es la figura por la cual se le confiere el poder de la palabra a una entidad muerta o sin voz, pero no supone identidad entre la ausencia de rostro y lo que funciona como máscara.
} 
porque ese pasado aún no pasó y ocurrirá en la temporalidad paradójica del advenimiento del recuerdo, quien escribe su propia vida debe inventarle una máscara a algo que no existe. El sujeto autoficcional tiene que inventarse rostros y poner en juego la indeterminación porque el pasado nunca pasó -seguiré profundizando en este punto en el siguiente apartado.

El trabajo con la verdad en las escrituras del yo, entonces, no está vinculado con la certificación de lo que se dice, sino con la afirmación simultánea de pasado y futuro -el advenimiento del pasado y el impacto del recuerdo. Como dice Alberto Giordano, "lo verdadero no se demuestra ni se revela, se fabrica a partir de un trabajo de selección y de desprendimiento que diferencia lo conveniente de lo que inmoviliza" (Giordano, 2011, p. 20). El carácter construible de una imagen de autor hace que no se la pueda asimilar directamente con la verdad que el autor declara. La figura del escritor es más bien un excedente de esa verdad.

\section{El devenir, ruina del recuerdo}

Todas las escrituras del yo están inmersas en un fondo de indiscernibilidad entre realidad y ficción. La autobiografía rechaza esta indecisión, se construye reactivamente para situarse del lado de la conciencia, de la memoria como síntesis y pulsión sistematizadora. La autoficción, en cambio, la afirma y permite que se evidencie en la escritura la temporalidad del recuerdo porque (profundizaremos esto a lo largo del apartado) el modo en el que el recuerdo ocurre neutraliza en acto la oposición.

Trabajaremos en este apartado con dos fuerzas en tensión que Alberto Giordano en Una posibilidad de vida (2006) identifica como la retórica de la memoria y la escritura de los recuerdos. Estas dos fuerzas son heterogéneas y simultáneas en el relato de la propia vida, y nos van a servir para explicar no sólo la singularidad de las experiencias autoficcionales sino también el modo en el que el recuerdo avanza en la escritura. La primera es la que se encarga de transformar la vida en relato, de ordenar, de dar sentido a una historia. La memoria permite que el relato de una vida se transforme en un encadenamiento verosímil de momentos verdaderos, presenta la temporalidad como sucesión de presentes. Implica una pulsión 
sistematizadora, una urgencia constructiva que se conecta con los procesos de autofiguración. Las escrituras de los recuerdos, en cambio, operan detalladamente. Los recuerdos están en plural porque se tienen recuerdos que se precipitan en el umbral de la memoria. Irrumpen como desprendidos de la voluntad de persuasión, se inscriben cuando la escritura deja de responder a las demandas del otro. Y ellos sí están representados como imágenes de una vida pasada. La insistencia por el recuerdo se le impone ineludiblemente a la voluntad sistematizadora del autobiógrafo.

En las escrituras del yo se nos presenta una persona no tal como fue, sino como cree estar siendo en el pasado, desde el punto de vista de lo que imagina llegará a ser, o mejor, habrá sido cuando termine de escribir, cuando intervenga el lector. No todo lo que recordamos sucedió tal como lo recordamos. La percepción de los tiempos y la relación con el propio pasado es peculiar en el acto autobiográfico. Cuando alguien quiere escribir la propia vida y contar sus vivencias pasadas, surge inevitablemente la temporalidad del recuerdo. Ese carácter imaginario del recuerdo es el que complejiza la determinación de las exigencias referenciales que supuestamente atañen a una escritura autobiográfica. Habría que descubrir cuál es el papel organizador de la memoria en esa dinámica y qué otra cosa hacen los modos disruptivos del recuerdo. Esta concepción del carácter ficcional de las escrituras del yo -¿hasta dónde es referencial y hasta dónde es ficcional?, ¿cuándo un autor miente y cuándo dice la verdad sobre sí mismo?- parece, al menos, reduccionista, y deja que se pierda de vista algo que tantos teóricos consideran lo esencial de la literatura, que es su carácter incierto o enigmático. Es decir, la hipótesis principal es que lo que domina en la autobiografía son las referencias de la memoria, de síntesis; en oposición a la autoficción que ofrece un debilitamiento de la fuerza organizadora y totalizadora de la memoria y una potenciación del recuerdo.

El tiempo íntimo acomoda temporalidades inconmensurables, presentes distintos e incompatibles que remiten a unidades de medidas diferentes. El autobiógrafo no se recuerda como fue, sino como está siendo lo que fue, según lo que quizás será. La temporalidad retroactiva enigmatiza la relación entre "aquello que deseamos ser (ahora), aquello que desearíamos ser (en el futuro) y aquello que deseamos haber sido (en el pasado)" (Rosa, 2004, p. 55). Hay en el recuerdo un poder alucinatorio del deseo que cues- 
tiona una realidad. Los hechos son recordados tal como nunca ocurrieron y allí es donde aparece lo incierto, lo impersonal (Rosa, 2004: 55). La memoria tiende a olvidar que el pasado coexiste con el presente y el recuerdo pone en evidencia que el pasado está pasando y está por pasar en el futuro. Por esto, escribir la propia vida no implica únicamente la recuperación de un pasado, la evocación de un mundo ido para siempre, sino la tarea y el drama de un ser que en un cierto momento de su historia se esfuerza en parecerse a su parecido, explica George Gusdorf en "Condiciones y límites de la autobiografía" (1991).

Allí, en el acto de recordar el pasado en el presente, el autobiógrafo imagina la existencia de otra persona que seguramente no es el mismo que en el mundo pasado. Y ese otro que fue (o mejor que no fue), simultáneamente, bajo ninguna circunstancia, ni por más que lo deseemos, existe en el presente. La autobiografía, entonces, evoca al pasado. Sí, pero para el presente y en el presente; y el pasado asumido en el presente es también un signo y una profecía del futuro. Los procesos autobiográficos están más orientados hacia el futuro que a la reconstrucción de un pasado. El futuro es el que induce la serie de evocación de los recuerdos. Y, como dice Ricoeur, Heidegger coloca la futuridad bajo el signo del ser-para-la-muerte. $\mathrm{El}$ adelantarse, el aproximarse a la muerte implica un recordar diferente; y simultáneamente el recuerdo -signado por ese adelantarse a la muerte futura- se configura no únicamente desde el pasado, sino desde el futuro.

El deseo de rememoración se conecta con la temporalidad del futuro anterior porque en el orden de la experiencia ningún presente está presente ante sí mismo en ningún momento ${ }^{5}$. Entendemos que la escritura de los recuerdos se rige por esta lógica de no correspondencia entre presente y presencia. Cuando recordamos, no recordamos los hechos tal como ocurrieron, sino justamente como no sucedieron, recordamos aquello que, en realidad, no nos ocurrió. En el recuerdo, el pasado no es únicamente pretérito, es lo que fuimos, lo que quisiéramos haber sido, lo que somos, y lo que

${ }^{5}$ Aquello que pasó, nunca pasó realmente, o mejor, nunca nos percatamos que eso pasaba, y por ende, pasó como posibilidades indeterminadas. El pasado siempre está pasando. Cuando llega a pasar, nos sorprende su aparición porque en realidad nunca nos había pasado: nunca lo vivimos en el presente y lo olvidamos mientras ocurría. Cuando decimos que el pasado pasó como posibilidades indeterminadas queremos decir que el futuro anterior de la temporalidad del recuerdo conjuga un futuro y un pasado por venir. 
querríamos ser. Se afirman allí simultáneamente pasado y futuro porque los recuerdos soportan la presencia actual de lo percibido anteriormente ${ }^{6}$.

Ahora bien, ¿cómo emergen entonces los recuerdos en nuestra memoria?, ¿qué relación hay entre el recuerdo de un acontecimiento y la imagen que nos hacemos de ellos en nuestra mente? Habría que observar de qué modo el trabajo del recuerdo en la escritura deviene imagen y, cuando eso sucede, la presentación de lo pasado se corrompe por la disrupción. El devenir-imagen del recuerdo, dice Ricoeur, afecta "la fidelidad en la que se resume la función veritativa de la memoria" (2000, p. 22). Ricoeur está repensando la teoría de Bergson para dar cuenta de las diferencias entre la evocación del recuerdo y la búsqueda de la memoria, que lo llevarán más adelante a pergeñar el devenir-imagen del recuerdo y el vínculo de éste con la ficción. Cita de Bergson:

A la memoria que se repite se opone la memoria que imagina: "para evocar el pasado en forma de imágenes, hay que poder abstraerse de la acción presente, hay que saber otorgar valor a lo inútil, hay que querer soñar. Quizás, sólo el hombre es capaz de un esfuerzo de ese tipo" (2000, p. 45).

La memoria y la imaginación tienen algo en común: la presencia de lo ausente; aunque en una se suspenda la posición de realidad y, en la otra, se mantenga la posición de la realidad anterior (67). La memoria forma parte de mi presente; es vivida, y no representada. No tenemos nada mejor que la memoria "para garantizar que algo ocurrió antes de que nos formásemos el recuerdo de ello" (23), dice Ricoeur. Como hábito, como pulsión sistematizadora, por lo tanto, se resiste a la invención. En cambio, la escritura de recuerdos proviene de la evocación en cuya búsqueda siempre hay afec-

\footnotetext{
${ }^{6}$ Las nociones de la nachträglich freudiana y el après coup lacaniano nos sirven para remitir al efecto del retardo. El recuerdo del pretérito irrumpe en el futuro de un modo que nunca esperamos porque nos sorprendemos, con esa aparición, de aquello que ya habíamos olvidado en el pasado. Las ruinas de un pasado insisten como fantasmagorías en el futuro. La autoficción viene a demostrar que aquello que sucedió en el pasado, no quedó en el pretérito, sino que sigue sucediendo de múltiples maneras en el futuro. Cuando digo que el narrador autoficticio cuenta su vida en clave ficticia, digo precisamente esto, que recuerda todo aquello que le pasó en el pretérito como nunca le ha pasado, y lo cuenta desde el futuro con la sorpresa con la que el recuerdo se sucede.
} 
ción -y no un razonamiento que da presencia o construye una historia-, soporta la carga del enigma de presencia actual de lo ausente percibido. "El recuerdo adviene como presencia de lo ausente" (47). Cuando los recuerdos se precipitan en el umbral de la memoria, reconocemos en ellos una dualidad: la impresión primera de vivir un acontecimiento, y la imagen que se forma en el recuerdo de aquella impresión. La pregunta de Ricoeur que deja de algún modo sin contestar es justamente cuál es la relación entre ambas, ¿̇es de copia, de semejanza? Y más tarde se vuelve a preguntar: “¿es el recuerdo una especie de imagen?" (66).

Ricoeur induce la secuencia percepción-recuerdo-ficción una vez que señaló las diferencias entre lo recordado, lo ficticio y lo pintado. En pocas palabras, lo pintado anticipa lo ficticio por su carácter indirecto, se trata de la presentación indirecta de la cosa física. En cambio lo ficticio está fuera de representación, y lo recordado se asocia a la percepción porque presenta las cosas del pasado y en eso conlleva una "dimensión posicional". Ahora bien, ¿qué entendemos por ficción? Me remito aquí a la concepción blanchotiana de la noción, que se conecta con la experiencia de la presentificación de lo ausente. Blanchot (1991 [1949]) entiende que el sentido de las palabras sufre una falta primordial porque demanda una verificación, un objeto preciso que verifique su contenido. En el lenguaje cotidiano, la cosa se ausenta por una negación, las palabras materializan lo que significan. Algo muy diferente sucede en el lenguaje de ficción porque se detiene en la negación, en el distanciamiento mismo por el cual la cosa vuelve a ser presente (re-presentado), explica Cueto en un ensayo sobre Blanchot. El lenguaje de la ficción no construye un mundo ficticio en el que nos abstraeríamos del mundo real, sino que nos devuelve a la profunda irrealidad de la que sin cesar nos separamos (Cueto, 1991, pp. 1-3).

Ricoeur dice que el recuerdo pertenece al mundo de la experiencia, en relación a los mundos de la fantasía de la irrealidad; y que entre recuerdo y ficción se salva un umbral de no-actualidad. Con el recuerdo lo ausente lleva la marca temporal de lo anterior. Y volviendo a la diferenciación que hacía Ricoeur entre memoria e imaginación, Blanchot aclara que el carácter simbólico de la imaginación no se limita a hacer presente lo que está ausente. Persigue a través de la cosa ausente, la ausencia que la constituye, lo irreal o la ficción. He aquí la definición del recuerdo que buscaba a lo lar- 
go de estas páginas: el recuerdo como ruina7 ${ }^{7}$ El recuerdo posee un carácter imaginario cuando pretende presentificar lo pasado, lo ya ausente. Pensar el recuerdo como ruina implica vislumbrar aquello que ya no está, y en esa mirada reparar en la ausencia que lo constituye. Es decir, recordar no sólo significa presentar al pasado como algo que ya no puede volver, sino hacer acto de esa ausencia. Ese sería, a nuestro modo de ver, el devenir-imagen -devenir-ruina- del recuerdo. El devenir imagen implica la toma de consistencia y apariencia de un objeto que se ha desprendido de lo imaginario.

Este carácter ambiguo-imaginario del recuerdo que en las escrituras del yo se presenta como ruinas de un pasado es el que de a poco socava la urgencia constructiva de la retórica de la memoria. He aquí lo esencial de la escritura autoficticia, que se diferencia de la autobiográfica. Para leer una escritura autobiográfica como autoficción -profundizando en la ambigüedad del gesto- habría que reparar en la potencia del recuerdo desbarrancando $o^{8}$ porque la autoficción trabaja con esa fuerza disruptiva y posibilita

${ }^{7}$ Es preciso que al hablar de las ruinas que constituyen nuestro pasado, ya sea intactas en la memoria o despedazadas en múltiples recuerdos imprecisos, remitamos directamente a El tiempo en ruinas de Marc Augé (2003). Si bien el autor realiza un recorrido etnológico sobre algunos de los monumentos o sitios arqueológicos más importantes del mundo, es posible utilizar algunas de sus ideas para pensar en el funcionamiento de la memoria y del recuerdo en el acto de contar la vida. Porque, según Augé, entre la experiencia vivida en el trabajo de campo de un etnólogo y la escritura de ese trabajo se instaura una distancia, "la distancia de uno mismo respecto de uno mismo" (12). Por ende, podemos trazar un paralelo significativo entre la exigencia del método de un antropólogo -la capacidad para relatar una historia a partir de un inventario de objetos perdidos- y la facultad de la memoria en tanto que ambos se construyen a partir de ruinas. La ruina tiene la apariencia formal del recuerdo porque ofrece un espectáculo del tiempo y posee su misma arbitrariedad. Los recuerdos provienen del olvido, aparecen sin avisar para hacernos reconocer que ese del pasado que se recuerda no es el que recuerda, justamente porque lo habíamos olvidado; y de repente es posible comprender la duración que transcurre en uno mismo. El olvido, fundamento de la memoria, crea espontáneamente imágenes insistentes y arbitrarias. Las ruinas como los recuerdos ofrecen un pasado que ha sido perdido de vista, que quedó olvidado pero que aún es capaz de decir algo. El recuerdo y la ruina advienen como presencia de lo ausente. "Un pasado al que el observador sobrevive" (88).

${ }^{8}$ Esta es una expresión acuñada en la tesis doctoral "Autoficción y melancolía en la narrativa de Fernando Vallejo" a partir del título de una de las autoficciones de Fernando Vallejo para dar cuenta de que la inestabilidad - la indiscernibilidad entre realidad y ficción, y la oscilación del personaje entre ser y no ser- se asienta sobre el desbarrancadero de los recuerdos. Es necesario aclarar que el desbarrancadero del recuerdo siempre está en tensión con ciertos procesos de autofiguración que propone el autor y que están íntimamente 
las condiciones como para que eso se potencie. Para mayor claridad, daré dos ejemplos extraídos de dos autoficciones de Fernando Vallejo, Los días azules (2005a) y Los caminos a Roma (2005b) respectivamente. En la primera, se relata una reacción peculiar de la madre del narrador, Liíta, cuando los padres compran con los abuelos maternos la finca de Santa Anita en un pueblo cerca de Medellín. El personaje de Líta representa el caos, el desorden de la casa: desalmada y castradora, no quiere contratar personal doméstico y utiliza a sus hijos como "sirvientes"; caprichosa, deja de cocinar para darle a sus innumerables hijos salchichas a toda hora del día. Liíta, de carácter obstinado -el "gen Rendón", lo llama Vallejo- comienza a ver de noche en Santa Anita un espectro. El espectro era un viejito con su alma en pena que "del Purgatorio no podía salir hasta que un alma caritativa no se sacara el entierro" (56). Así comienza un emprendimiento familiar para encontrar el cadáver que Liíta veía en sueños. Tumban el zapote, echan tierra a varios árboles, destruyen techos, rompen pisos, y la obsesión de la madre, que no cesa, culmina con la destrucción total de la finca: "El tono era de amargo reproche: lo tomaron por aprobación. De cuarto en cuarto terminaron durmiendo todos en promiscuidad de tugurio, en el de los abuelos: el último en caer. Así terminó la finca de Santa Anita: por una ambición" (58). Lo mismo sucede cuando a Liíta se le ocurre construir una piscina en el patio de la casa de Medellín, pero al tiempo, luego de una caída del hermano Silvio, por obra del remordimiento decide clausurarla. Más tarde, decide sacarle la tierra y llenarla de agua nuevamente, porque es mejor que los niños aprendan a nadar, para después volver a taparla porque no vaya a ser que de un calambre ella se ahogue. Y "Así el ciclo se empezó a repetir ab aeterno: era una piscina mágica que se vaciaba de agua para llenarse de tierra y viceversa, al ritmo de una obsesión" (79).

Estos episodios extravagantes interrumpen los recuerdos de infancia, descolocan la continuidad del relato cronológico y provocan cierta incertidumbre en el lector. La escritura impone la transformación, la manipula-

relacionados con la construcción de una imagen de autor en y por fuera de los textos. Es decir, ese derrumbe de la sistematización de la historia que construye la memoria es llevado a cabo no sólo por el carácter ambiguo e imaginario inherente al proceso de recordar, sino también, y simultáneamente, por el carácter propositivo de la construcción de una imagen de autor determinada. 
ción de lo vivido. En la exageración de llevar lo ocurrido hasta el extremo de lo inimaginable, ironizando al mismo tiempo, por supuesto, con la personalidad de la madre, el narrador logra que el recuerdo devenga ficción. Vallejo se excede y en el exceso provoca la ambigüedad: no sabemos si aquello que nos cuenta sucedió, si algo de aquello sucedió, si es pura invención o si juega a confundirnos. Poco importa qué de lo que cuenta el sujeto autoficcional es real. No importa si la locura de la madre destruyó una casa, o si realmente comieron durante un año sólo salchichas. Y menos interesa sin afán de entrar en polémica con Jacques Joset, si estas muertes o asesinatos son manifestaciones de deseos irreprimibles o pulsiones sofocadas del autor (Joset, 2010, pp. 101-125). Porque pretender develar lo que tiene de verdad la autoficción es no sólo no haber comprendido el estatuto ambiguo del género, sino tampoco tolerar la incertidumbre, que siempre es un valor estimable tratándose de este tipo de literatura. La autoficción es irreductiblemente ambigua; no es posible, por más tentación que genere -sobre todo a Joset, que reclama una biografía del autor colombiano que devele los incidentes de la vida real del escritor-, no es posible, insistimos, inclinar la balanza hacia uno u otro pacto porque es precisamente allí donde se afirma la suspensión de la posibilidad de decidir y donde reside su mayor potencia literaria.

Aunque no hay que perder de vista las relaciones de fuerza entre la retórica de la memoria y la escritura de los recuerdos, sí hay que señalar los modos en que la construcción de una historia como horizonte que plantea la pulsión de la memoria se debilita en relación con la potenciación del derrumbe que provoca el recuerdo en el género autoficticio. Por esto, en las autoficciones el autor suele jugar con una historia contada de diversas formas, inventarse rostros, nuevas personalidades, o suele contradecirse hasta el punto de perder credibilidad por parte del lector.

\section{Conclusiones}

Sería interesante concluir el texto reflexionando sobre el análisis que realiza Philippe Forest (2001), en Le roman, le je, porque coloca la autoficción -él la llama específicamente "hétérobiographie"- en el terreno de lo real, de la experiencia y de lo imposible, algo que intentamos hacer a lo largo de 
estas páginas. Es decir, la autoficción, para Forest, designa lo real como un imposible y, por ende, no traduce otra cosa que un "sentimiento radical de pérdida". Un sentimiento radical de pérdida que, en el sentido de nuestra aproximación, se relaciona con los mecanismos del recuerdo en el trabajo de la escritura.

El desbarrancadero del recuerdo (la potencia disruptiva con la que el recuerdo emerge en el relato de la propia vida) siempre está en tensión con ciertos procesos de autofiguración que propone el autor y que están íntimamente relacionados con la construcción de una imagen de autor en y por fuera de los textos. Es decir, ese derrumbe de la sistematización de la historia que construye la memoria del que venimos hablando es llevado a cabo no sólo por el carácter ambiguo e imaginario inherente al proceso de recordar sino también y simultáneamente por el carácter propositivo de una construcción de una imagen de autor determinada. Ni engaño ni mentira, ni verdad ni falsedad, la autoficción se basa en la posibilidad de presentificar lo perdido desde lo imaginario del recuerdo. En este sentido, se podría afirmar que lo esencial de la literatura autoficticia tiene que ver con las formas estéticas en que resuelve la tensión entre la memoria, que se preserva de la ambigüedad, y el recuerdo, que se precipita, insistente, al borde del desbarrancadero.

\section{Referencias}

Agamben, G. (2000). Lo que queda de Auschwitz. Valencia: Pre-Textos.

Alberca, M. (2007). El pacto ambiguo. De la novela autobiográfica a la autoficción. Madrid: Biblioteca Nueva.

Augé, M. (2003). Tiempos en ruinas. Barcelona: Editorial Gedisa.

Blanchot, M. (1991 [1949]). El lenguaje de la ficción. Boletín del Grupo de Estudios de Teoría Literaria, 1, marzo. (Traducción: Sandra Contreras). Rosario: UNR. Publicado originalmente en 1949, La part du feu. París: Gallimard.

Catelli, N. (2007). En la era de la intimidad seguido de: el espacio autobiográfico. Rosario: Beatriz Viterbo Editora.

Colonna, V. (2004). Autofiction et autres mythomanies littéraires. Auch: Tristam.

Cueto, S. (1991). El lenguaje de la ficción. Boletín del Grupo de Estudios de Teoría Literaria, 1, marzo. Rosario: UNR. 
Cusset, C. (2007). L' ecriture de soi: un projet moraliste. En J.L. Jeanelle y C. Viollet (dir.), Genese et Autofiction (pp. 197-211). Bruxelles: Academia Bruylant, Louvain-la-Neuve.

DeToro, A. (1999). La nouvelle autobiographique posmoderne oul'impossibilité d'une histoire a la première personne: Robbe-Grillet, Le miroir qui revient et de Doubrovsky Le livre brisé. Conférence, Faculté de Philologie de l'Université de Leipzig. Disponible en http://home.uni-leipzig.de/detoro/ wp-content/uploads/2014/03/LaNouvelle.pdf.

Doubrovsky, S. (2001). Fils. París: Gallimard.

Duque-Estrada, E. M. (2009). Devires autobiográficos. A atualidade da escrita de si. Rio de Janeiro: NAU/Editora Puc-Rio.

Forest, P. (2001). Le roman, le je. Nantes: Plein Feux. (2007). La vie est un roman. En J. L. Janelle y C. Viollet (dir.), Genese et Autofiction (pp. 211-221). Bruxelles: Academia Bruylant, Louvain-la-Neuve. Gasparini, P. (2004). Est-il je? Paris: Editions du Seuil. (2008). Autofiction. Une aventure du langage. Paris: Editions du Seuil.

Genette, G. (1993). Ficción y dicción. Barcelona: Editorial Lumen.

Giordano, A. (2006). Una posibilidad de vida. Escrituras íntimas. Rosario: Beatriz Viterbo Editora. (2011). Vida y obra. Otra vuelta al giro autobiográfico. Rosario: Beatriz Viterbo Editora.

Gusdorf, George. (1991). Condiciones y límites de la autobiografía. Anthropos, 29, 9-18, diciembre.

Joset, J. (2010). La muerte y la gramática. Los derroteros de Fernando Vallejo. Buenos Aires: Taurus.

Lejeune, P. (1975). Le pacte autobiographique. Paris: Editions du Seuil.

Molloy, S. (1966). Acto de presencia. La escritura autobiográfica en Hispanoamérica. México: Fondo de Cultura Económica.

Ricoeur, P. (2000). La memoria, la historia, el olvido. Buenos Aires: Fondo de Cultura Económica.

Rosa, N. (2004). El arte y el olvido y tres ensayos sobre mujeres. Rosario: Beatriz Viterbo Editora.

Schmitt, A. (2010). Je réel/je fictif. Au-delà d'une confusion postmoderne. Toulouse: Presses Universitaires du Mirail.

Topuzian, M.(2014). Muerte y resurrección del autor (1963-2005). Santa Fe: Universidad Nacional del Litoral.

Vallejo, F. (2005a), Los días azules. Barcelona: Alfaguara.

Vallejo, F. (2005b). Los caminos a Roma. Barcelona: Alfaguara.

Vilain, P. (2009). L'autofiction en théorie. Paris: Grasset, Les Editions de la Transparence. 